\title{
Catechin Hydrate Augments the Antibacterial Action of Selected Antibiotics against Staphylococcus aureus Clinical Strains
}

\author{
Maria Miklasińska ${ }^{1, \dagger}$, Małgorzata Kepa ${ }^{1, \dagger}$, Robert D. Wojtyczka ${ }^{1}$, Danuta Idzik ${ }^{1}$, \\ Arkadiusz Dziedzic ${ }^{2}$ and Tomasz J. Wąsik ${ }^{1, *}$ \\ 1 Department of Microbiology and Virology, School of Pharmacy and Division of Laboratory Medicine in \\ Sosnowiec, Medical University of Silesia, ul. Jagiellońska 4, 41-200 Sosnowiec, Poland; \\ maria.miklasinska@o2.pl (M.M.); mkepa@sum.edu.pl (M.K.); rwojtyczka@sum.edu.pl (R.D.W.); \\ didzik@sum.edu.pl (D.I.) \\ 2 Department of Conservative Dentistry with Endodontics, Medical University of Silesia, Katowice, \\ Pl. Akademicki 17, 41-902 Bytom, Poland; adziedzic@sum.edu.pl \\ * Correspondence: twasik@sum.edu.pl; Tel.: +48-32-364-1621; Fax: +48-32-364-1622 \\ + These authors contributed equally to this work.
}

Academic Editor: Peter J. Rutledge

Received: 17 December 2015; Accepted: 18 February 2016; Published: 20 February 2016

\begin{abstract}
Synergistic effects between commonly used antibiotics and natural substances may be an alternative to conventional antibacterial therapies. The objective of the presented study was to assess the in vitro antibacterial activity of catechin hydrate $(\mathrm{CH})$ and evaluate the interactions of $\mathrm{CH}$ with selected antibiotics using Staphylococcus aureus clinical and reference strains. $\mathrm{CH}$ displayed diverse activity towards examined S. aureus strains, with minimal inhibitory concentrations (MICs) ranging from 256 to $2048 \mu \mathrm{g} / \mathrm{mL}$. The interaction between $\mathrm{CH}$ and antibiotics was assessed by an E-test. The most significant synergistic effects were noticed for $\mathrm{CH}$ in combination with clindamycin and erythromycin. For cefoxitin and vancomycin a decrease of MIC values in the presence of $\mathrm{CH}$ was also observed, but it did not reach statistical significance. The obtained results demonstrate that $\mathrm{CH}$ shows antimicrobial activity against Staphylococcus aureus clinical strains. What is more, we proved a synergistic effect of $\mathrm{CH}$ with erythromycin and clindamycin.
\end{abstract}

Keywords: catechin hydrate; antibacterial activity; Staphylococcus aureus

\section{Introduction}

The research concept of the study presented herein resulted from the worldwide escalation of clinical infections caused by multi-drug resistant microorganisms and the spread of resistance among bacteria to commonly used antibiotics. At present one of the main public health problems is associated with the infections caused by multi-drug resistant bacteria, so it is clear that the search for new antibacterial agents is absolutely necessary [1]. Methicillin resistant Staphylococcus aureus (MRSA) strains, which are resistant to nearly all current anti-staphylococcal drugs, pose a particular threat, especially for hospitalized patients with decreased immunity [2,3]. The spread of the drug resistance among $S$. aureus strains has stimulated the search for the new strategies for the treatment of multi-drug resistance infections. The best way to fight such infections would be to develop a new class of potent antibacterial agents, yet such an approach is extremely expensive and time consuming. What is more, the probability of success is rather disputable. Another way to overcome bacterial resistance is to find compounds which can improve the antibacterial effect of commonly used antibiotics [3,4]. Many studies have demonstrated that some natural flavonoids have antimicrobial properties against a 
broad spectrum of microorganisms and may be an alternative to conventional therapy [5-15], therefore we undertook research to discover new natural compounds with antibacterial properties which can contribute to the fight against multi-drug resistant bacteria.

Catechin is a flavonoid (flavan-3-ol) found, for example, in tea, wine, some fruits, vegetables and chocolate [16]. It has been proved that catechin has radical scavenging [17-19] metal-chelating [20,21] and antiproliferative effects [22,23]. It also has been demonstrated that (+)-catechin has the ability to inhibit HIV-1 reverse transcriptase in vitro [12,24]. Many studies have indicated that flavan-3-ols also possess antibacterial activity. The antimicrobial properties of tea have been known for over a century and its bacteriostatic and bactericidal effects have been assessed [25]. Catechins possess the ability to bind to artificial lipid bilayers [26-30]. It has been shown that the catechins (-)-epicatechin gallate and (-)-epigallocatechin gallate can sensitize MRSA strains to $\beta$-lactam antibiotics, including methicillin [25,31-34]. It has been also reported that epicatechin gallate and epigallocatechin gallate acted as a nor $A$ gene suppressors [35] and decreased $\beta$-lactam MICs to the antibiotic breakpoint, thus increasing the antimicrobial activity of those antibiotics $[3,31,33,36,37]$. Kubo et al. proved the direct antibacterial activity of alkyl gallates [38].

The majority of conducted studies on the antimicrobial activity of catechins focused on epicatechin and gallates of epicatechin $[25,32,33,37,39,40]$ as the main representatives of flavonoids but reports on antimicrobial properties of catechin are scarce. Research on the antibacterial activity of $(+)$-catechin has demonstrated that it has an ability to reduce the biosynthesis of the virulence factors which control a quorum-sensing system in Pseudomonas aeruginosa [41]. It has also been shown that polymerized catechin suppresses the activity of Staphylococcus aureus $\alpha$-toxin and that $\mathrm{CH}$ is an effective urease inhibitor in Staphylococcus saprophyticus strains [42,43]. The above observations prompted us to investigate in vitro antimicrobial activity of $\mathrm{CH}$ against $S$. aureus clinical strains.

\section{Results}

\subsection{Identification of Examined Strains}

All the examined strains were classified as members of Staphylococcus aureus species. The profiles of resistance to methicillin and $\mathrm{MLS}_{\mathrm{B}}$ antibiotics obtained for the analyzed strains are presented in Table 1.

\subsection{Antimicrobial Activity of the Catechin Hydrate (CH)}

$\mathrm{CH}$ at the concentrations used in this study inhibited the growth of all tested staphylococci strains. The MICs obtained for $\mathrm{CH}$ ranged from 256 for the most susceptible strains, to $2048 \mu \mathrm{g} / \mathrm{mL}$ for the most resistant strains, with a median values of $1024 \mu \mathrm{g} / \mathrm{mL}$ (Table 1 ). The antimicrobial activity of $\mathrm{CH}$ against the examined $S$. aureus strains was identical for 16 strains, with MICs at $1024 \mu \mathrm{g} / \mathrm{mL}$. CH showed the strongest antibacterial activity against Staphylococcus aureus ATCC 25923, S. aureus ATCC 6538 reference strains and $S$. aureus 13 clinical strain with MICs of $256 \mu \mathrm{g} / \mathrm{mL}$, while against S. aureus 1, 3, 6, 17 strains $\mathrm{CH}$ demonstrated weaker antibacterial activity what resulted in much higher MIC values: $2048 \mu \mathrm{g} / \mathrm{mL}$ (Table 1). Comparison of MRSA and MSSA strains demonstrated that in both cases the MIC values ranged from 256 to $2048 \mu \mathrm{g} / \mathrm{mL}$. A statistical analysis indicated that there were no significant differences between MIC values for MRSA and MSSA strains $(p=0.203)$, as well as for $\mathrm{MLS}_{\mathrm{B}}$ negative, $\mathrm{kMLS}_{\mathrm{B}}$ and $\mathrm{iMLS}_{\mathrm{B}}$ strains $(p=0.632)$.

\subsection{Combined in Vitro Effects of $\mathrm{CH}$ and Antibiotics}

The antimicrobial activity of $\mathrm{CH}$ with erythromycin (E), clindamycin (DA), cefoxitin (FOX) and vancomycin (VA) is shown Table 2. Addition of one-fourth of the MIC of $\mathrm{CH}$ to the Mueller Hinton agar (MHA) increased sensitivity of the tested staphylococci to all examined antibiotics. In case of $\mathrm{E}$ $(p=0.009)$, and DA $(p=0.006)$ the results reached statistical significance. Decrease of MICs for VA-CH combination $(p=0.605)$ and FOX-CH $(p=0.064)$ combination was not significant. 
Table 1. Profile of resistance to methicillin and $\mathrm{MLS}_{\mathrm{B}}$ antibiotics for examined strains and MIC of $\mathrm{CH}$ against examined S. aureus strains.

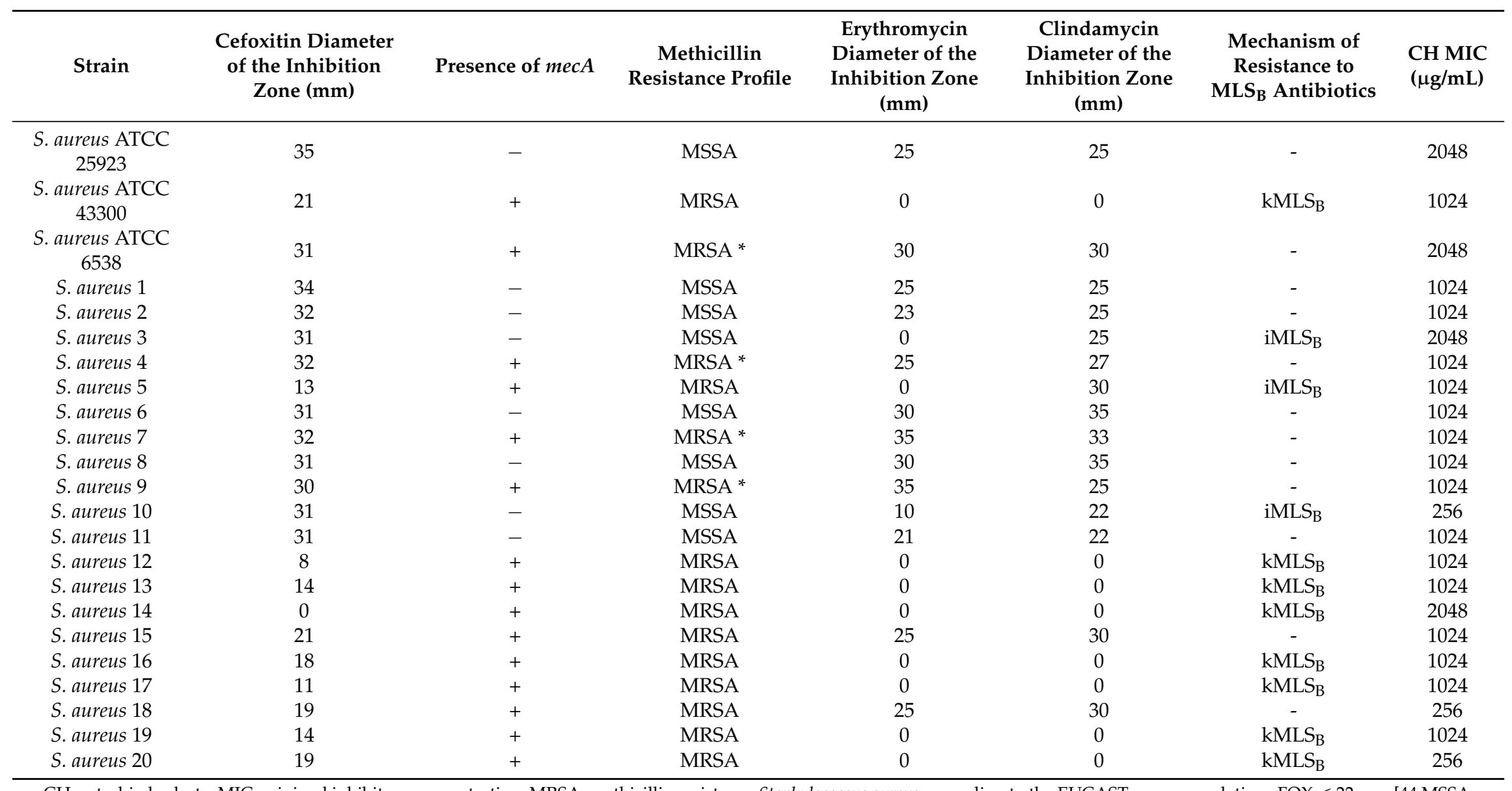

CH: catechin hydrate, MIC: minimal inhibitory concentration, MRSA: methicillin resistance Staphylococcus aureus, according to the EUCAST recommendations FOX $\leqslant 22$ mm [44 MSSA methicillin susceptible Staphylococcus aureus, according to the EUCAST recommendations FOX > 22 mm [44], MRSA *: phenotype and genotype discordance, kMLS ${ }_{B}$ : constitutive

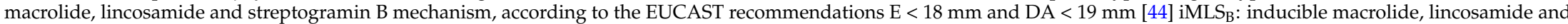
streptogramin B mechanism, according to the EUCAST recommendations E $<18$ and DA $\geqslant 22$ (D-shaped zone of inhibition around clindamycin with flattening towards erythromycin disc [44]. 
Table 2. The combined antibacterial effects of catechin hydrate and erythromycin, clindamycin, cefoxitin and vancomycin on Staphylococcus aureus examined strains (MIC values expressed in $\mu \mathrm{g} / \mathrm{mL}$ ).

\begin{tabular}{|c|c|c|c|c|c|c|c|c|c|c|c|c|}
\hline Bacterial Strain & $\mathrm{E}$ & $\mathrm{E}+\mathrm{CH}$ & $\Delta \%$ & DA & $\mathrm{DA}+\mathrm{CH}$ & $\Delta \%$ & FOX & $\mathrm{FOX}+\mathrm{CH}$ & $\Delta \%$ & VA & $\mathrm{VA}+\mathrm{CH}$ & $\Delta \%$ \\
\hline S. aureus ATCC 25923 & 0.38 & 0.50 & $32 \%$ & 0.064 & 0.064 & $0 \%$ & 1 & 1 & $0 \%$ & 0.75 & 1 & $33 \%$ \\
\hline S. aureus ATCC 43300 & 256 & 256 & $0 \%$ & 256 & 256 & $0 \%$ & 12 & 8 & $-33 \%$ & 0.38 & 0.75 & $97 \%$ \\
\hline S. aureus ATCC 6538 & 0.064 & 0.19 & $197 \%$ & 0.023 & 0.032 & $39 \%$ & 2 & 1.5 & $-25 \%$ & 0.50 & 0.38 & $-24 \%$ \\
\hline S. aureus 1 & 0.50 & 0.19 & $-62 \%$ & 0.064 & 0.032 & $-50 \%$ & 2 & 1.5 & $-25 \%$ & 0.75 & 0.50 & $-33 \%$ \\
\hline S. aureus 2 & 0.50 & 0.25 & $-50 \%$ & 0.064 & 0.064 & $0 \%$ & 0.75 & 1.5 & $100 \%$ & 0.38 & 0.75 & $97 \%$ \\
\hline S. aureus 3 & 256 & 256 & $0 \%$ & 0.023 & 0.016 & $-30 \%$ & 1.5 & 1.5 & $0 \%$ & 0.50 & 0.50 & $0 \%$ \\
\hline S. aureus 4 & 0.38 & 0.064 & $-83 \%$ & 0.064 & 0.023 & $-64 \%$ & 2 & 1.5 & $-25 \%$ & 0.50 & 0.38 & $-24 \%$ \\
\hline S. aureus 5 & 256 & 4 & $-98 \%$ & 0.094 & 0.064 & $-32 \%$ & 256 & 24 & $-91 \%$ & 0.75 & 0.50 & $-33 \%$ \\
\hline S. aureus 6 & 0.50 & 0.25 & $-50 \%$ & 0.064 & 0.032 & $-50 \%$ & 1.5 & 2 & $33 \%$ & 0.38 & 0.38 & $0 \%$ \\
\hline S. aureus 7 & 0.38 & 0.125 & $-67 \%$ & 0.032 & 0.016 & $-50 \%$ & 1 & 0.25 & $-75 \%$ & 0.50 & 0.25 & $-50 \%$ \\
\hline S. aureus 8 & 0.19 & 0.064 & $-66 \%$ & 0.032 & 0.016 & $-50 \%$ & 1.5 & 1 & $-33 \%$ & 0.38 & 0.50 & $32 \%$ \\
\hline S. aureus 9 & 0.38 & 0.19 & $-50 \%$ & 0.064 & 0.016 & $-75 \%$ & 1 & 2 & $100 \%$ & 0.38 & 0.50 & $32 \%$ \\
\hline S. aureus 10 & 32 & 32 & $0 \%$ & 0.047 & 0.047 & $0 \%$ & 2 & 2 & $0 \%$ & 0.38 & 0.38 & $0 \%$ \\
\hline S. aureus 11 & 0.38 & 0.094 & $-75 \%$ & 0.047 & 0.023 & $-51 \%$ & 1.5 & 2 & $33 \%$ & 0.38 & 0.25 & $-34 \%$ \\
\hline S. aureus 12 & 256 & 256 & $0 \%$ & 256 & 256 & $0 \%$ & 256 & 256 & $0 \%$ & 0.75 & 0.50 & $-33 \%$ \\
\hline S. aureus 13 & 256 & 256 & $0 \%$ & 256 & 256 & $0 \%$ & 32 & 32 & $0 \%$ & 0.75 & 0.50 & $-33 \%$ \\
\hline S. aureus 14 & 256 & 256 & $0 \%$ & 256 & 256 & $0 \%$ & 256 & 256 & $0 \%$ & 0.75 & 0.50 & $-33 \%$ \\
\hline S. aureus 15 & 0.25 & 0.38 & $52 \%$ & 0.064 & 0.047 & $-27 \%$ & 8 & 6 & $-25 \%$ & 0.38 & 0.75 & $97 \%$ \\
\hline S. aureus 16 & 256 & 256 & $0 \%$ & 256 & 256 & $0 \%$ & 256 & 256 & $0 \%$ & 0.50 & 0.50 & $0 \%$ \\
\hline S. aureus 17 & 256 & 256 & $0 \%$ & 256 & 256 & $0 \%$ & 256 & 2 & $-99 \%$ & 0.38 & 0.38 & $0 \%$ \\
\hline S. aureus 18 & 0.38 & 0.25 & $-34 \%$ & 0.047 & 0.047 & $0 \%$ & 6 & 1 & $-83 \%$ & 0.50 & 0.38 & $-24 \%$ \\
\hline S. aureus 19 & 256 & 256 & $0 \%$ & 256 & 256 & $0 \%$ & 256 & 256 & $0 \%$ & 0.50 & 0.50 & $0 \%$ \\
\hline S. aureus 20 & 256 & 256 & $0 \%$ & 256 & 256 & $0 \%$ & 12 & 4 & $-67 \%$ & 0.38 & 0.38 & $0 \%$ \\
\hline Median & 0.5 & 0.5 & 0 & 0.064 & 0.047 & 0 & 2 & 2 & 0 & 0.50 & 0.5 & 0 \\
\hline Q1 & 0.38 & 0.19 & 0 & 0.047 & 0.023 & 0 & 1.5 & 1,5 & 0 & 0.38 & 0.38 & -32 \\
\hline Q3 & 256 & 256 & 62 & 256 & 256 & 50 & 256 & 32 & 33 & 0.75 & 0.5 & 33 \\
\hline$p$ & & 0.009 & & & 0.006 & & & 0.064 & & & 0.605 & \\
\hline
\end{tabular}

CH: catechin hydrate, E: erythromycin, DA: clindamycin, FOX: cefoxitin, VA: vancomycin, Q1: lowest quartile, Q3: upper quartile. 
The diminished MICs in the presence of $\mathrm{CH}$ ranged from 24 to even 99\% (Table 2). The most susceptible strains to a synergistic effect of the $\mathrm{CH}$ and antibiotics were $S$. aureus 1, 4, 5 and 7 strains, which were more sensitive to all antibiotics after MHA supplementation with $\mathrm{CH}$. The strongly augmented effect of $\mathrm{CH}$ in the presence of all antibiotics was also noted for $S$. aureus strain 8, except for VA, S. aureus strain 11 except for FOX and S. aureus strain 18 except for DA.

Some strains were found to be resistant to $\mathrm{CH}$ in combination with the tested antibiotics. No MIC changes were observed in S. aureus strains 10,16 and 19. The level of resistance to E, DA and FOX was not affected by the MHA supplementation with $C H$ for $S$. aureus strains 12, 13, 14, 16, 17, 19, 20. Furthermore, for some strains and some antibiotics after $\mathrm{CH}$ addition antagonistic interactions were noted. The increases of MICs ranged from 32\% to even 197\% (Table 2).

Statistical analysis excluded the significance of the differences between the changes of MIC values for MRSA and MSSA strains for $\mathrm{E}-p=0.363$; DA $-p=0.221$, FOX $-p=0.082$ and VA $-p=0.391$. There were no significant differences between changes of MICs obtained for $M_{L} S_{B}$ negative $v s$. KMLS $_{B}$ and iMLS $\mathrm{B}_{\mathrm{B}}$ staphylococci in case of $\mathrm{E}-p=0.166$; FOX $-p=0.621$ and VA $-p=0.922$, while for DA statistical analysis revealed significant differences $(p=0.038)$. Further analysis demonstrated that strains with $\mathrm{KMLS}_{\mathrm{B}}$ phenotype of resistance showed lower susceptibility to the combination of $\mathrm{CH}$ with DA than MLS $_{B}$ negative strains.

\section{Discussion}

It is well know that catechins have antimicrobial activity against both Gram-positive and Gram-negative bacteria. Catechins exert indirect antimicrobial activity by modifying the resistance level to antibiotics and by changing gene expression associated with the bacterial virulence. The majority of the research on the flavonoids antibacterial activity was focused on epicatechin and gallates of epicatechin alone or in the combination with antibacterial agents $[25,27,32,33,39,40,45]$. To our knowledge the present study is one of the first to explore the antimicrobial activity of $\mathrm{CH}$.

Many studies have showed that catechins possess the capacity to reverse oxacillin resistance in $S$. aureus [26,32,36,37], which is also observed in epicatechin gallate. Stapleton et al. studied the antibacterial activity of catechins, including (+)-catechin on three S. aureus strains-BB568, EMRSA-15 and EMRSA-16-and demonstrated that MRSA strains were insensitive to (+)-catechin with MICs $>256 \mathrm{mg} / \mathrm{L}$ [31]. In our study the MIC values of $\mathrm{CH}$ obtained for MRSA reference and clinical strains ranged from 256 to $2048 \mu \mathrm{g} / \mathrm{mL}$, with a median value of $1024 \mu \mathrm{g} / \mathrm{mL}$. A study on the antimicrobial activity of catechins alone and in combination with oxacillin against MRSA strains was carried out by Stapleton et al. in 2004 on the strains described above [26]. The obtained MIC values were the same as the ones in the authors' previous work, so to enhance the capacity of catechins to interact with cytoplasmic membrane and consequently to increase their antibacterial activity the acyl chains were incorporated into (+)-catechin. MICs obtained after addition of acyl chains were smaller and ranged from 16 to $256 \mathrm{mg} / \mathrm{L}$ [26].

Park et al. studied the antibacterial activity of 3-O-alkyl analogues of (+)-catechin against Gram-positive and Gram-negative bacteria and demonstrated that alkylation improved the activity of a parent compound and antibacterial properties increased in relations with the number of carbons in the alkyl chain [46]. Similarly, Holloway et al. in their study tried to increase antibacterial activity of catechin and found out that metal (II) ions such as copper (II) sulphate and iron (II) enhance antibacterial activity of (+)-catechin against $S$. aureus strains due to increased $\mathrm{H}_{2} \mathrm{O}_{2}$ production after metal ions supplementation [21]. Perhaps the incorporation of substituents to $\mathrm{CH}$ could also increase its antibacterial properties.

The studies on the combined action of catechin and epicatechin gallate with $\beta$-lactams against standard and clinical MRSA strains were carried out by Qin et al. [3]. Catechin alone did not increase the susceptibility of MRSA strains to $\beta$-lactam antibiotics with MICs $>1024 \mathrm{mg} / \mathrm{L}$. In our study we showed that $\mathrm{CH}$ alone increased susceptibility of MRSA strains to the $\beta$-lactam antibiotic cefoxitin, but it did not prove to be statistically significant. However, Qin et al. reported that a catechin-epicatechin gallate 
combination increased MRSA strains susceptibility to $\beta$-lactam antibiotics and this effect was related to the catechin, but not to epicatechin gallate concentration. What is more, catechin showed higher activity than cis forms of non-galloylated catechins such as (-)-epicatechin or (-)-epigallocatechin in enhancing MRSA susceptibility to $\beta$-lactam antibiotics. Qin et al. indicated that catechin-epicatechin gallate combination enhances activity of such antibiotics as ampicillin, ampicillin/sulbactam, cefazolin, cefepime and imipenem/cilastatin which usually cannot be used in the treatment of MRSA infections because of bacterial resistance. The authors suggested that these antibiotics could be used in treatment when combined with catechin and epicatechin gallate. Moreover, they pointed out that analyzed flavonoid-antibiotic combinations did not show similar effects when combined with non- $\beta$-lactam antibiotics. The authors suggested that the enhancement of an antibacterial effect of $\beta$-lactam antibiotics by catechin-epicatechin combination might be related to the accumulation of antibiotics and inhibition of efflux pump gene expression. In our work we demonstrated that $\mathrm{CH}$ decreased the MIC values of both $\beta$-lactam (cefoxitin) and non- $\beta$-lactam (erythromycin, clindamycin and vancomycin) antibiotics and the diminished of MICs in the presence of $\mathrm{CH}$ ranged from $24 \%$ to even $99 \%$. Our research proved that $\mathrm{CH}$ exerted an antimicrobial activity toward the examined S. aureus strains. What is more, our results suggest that the combined action of $\mathrm{CH}$ and selected antibiotics demonstrates a synergistic effect. The MICs of CH against the tested staphylococci ranged from 256 to $2048 \mu \mathrm{g} / \mathrm{mL}$ and the vast majority of examined strains had a MIC of $1024 \mu \mathrm{g} / \mathrm{mL}$. The statistical analysis showed that varying sensitivity of the tested staphylococci to $\mathrm{CH}$ was not affected by a methicillin resistance profile or a phenotype of resistance to $\mathrm{MLS}_{\mathrm{B}}$ antibiotics. The mechanism of $\mathrm{CH}$ effect on bacterial cells is still unknown and we can only suppose that the most likely cause of discrepancies of the obtained MICs is related to the intra-species diversity, so further studies are needed to investigate the mechanism of the $\mathrm{CH}$ effect on bacterial cells.

Our analysis of the influence of $\mathrm{CH}$ on the antibacterial properties of the selected antibiotics revealed a substantial reduction of the MICs for all antibiotics. The most noticeable synergistic effect was observed for $\mathrm{CH}$ in combination with erythromycin and clindamycin. Synergism between $\mathrm{CH}$ and vancomycin, $\mathrm{CH}$ and cefoxitin was also observed, but it did not prove to be statistically significant. The profile of resistance to methicillin did not influence MICs changes, but the MIC changes of clindamycin following the $\mathrm{CH}$ addition were affected by the profile of resistance to $\mathrm{MLS}_{\mathrm{B}}$ antibiotics. Strains resistant to clindamycin, erythromycin and cefoxitin (S. aureus ATCC 4330, S. aureus 12, 13, 14, $16,17,19,20)$ were insensitive to $\mathrm{CH}-\mathrm{E}, \mathrm{CH}-\mathrm{DA}$ and $\mathrm{CH}-\mathrm{FOX}$ combinations and statistical analysis proved that strains with a constitutive phenotype of resistance were less susceptible to $\mathrm{CH}$-clindamycin combination than staphylococci without $\mathrm{MLS}_{\mathrm{B}}$ phenotype, what indicates that $\mathrm{CH}$ is not effective against $\mathrm{kMLS}_{\mathrm{B}}$ strains.

Since $\mathrm{CH}$ showed the same action against sensitive and multi drug-resistant $S$. aureus strains it is therefore possible that the $\mathrm{CH}$ can be used in the treatment of both multi-drug resistant and drug susceptible bacterial infections. In this context, it is worth noting that the antibacterial activity of catechin can be improved by chemical modifications, as previous studies have showed $[21,26]$. The synergy between $\mathrm{CH}$ and antibiotics indicates the potential application of compound combinations as an efficient, novel therapeutic tool for treatment of multi-drug resistance infections.

\section{Materials and Methods}

\subsection{Bacterial Strains and $\mathrm{CH}$}

The antimicrobial activity of $\mathrm{CH}$ was assessed against 20 S. aureus strains isolated from clinical wound samples, and three reference strains of S. aureus: ATCC 25923, S. aureus ATCC 43300 and S. aureus ATCC 6538. To ensure the homogeneity of the examined samples all tested strains were collected from surgical wounds. All bacterial strains were stored for further analyses in Soy Broth medium with $20 \%$ of glycerol at $-80^{\circ} \mathrm{C}$. The $\mathrm{CH}$ used in this study was obtained from Sigma Chemical Co. (St. Louis, MO, USA) and dissolved in DMSO immediately prior to use. 


\subsection{Identification of Examined Strains}

All the examined isolates were identified by the conventional methods including colony morphology, hemolysis, catalase and coagulase tests and the anaerobic fermentation of mannitol. Catalase and coagulase positive strains where identified by the API STAPH test (bioMerieux, Marcy-l'Étoile, France) according to the manufacturer's instruction. The PCR-RFLP technique was also performed. For PCR-RFLP analysis, bacterial genomic DNA was extracted with the GeneMATRIX Tissue \& Bacterial DNA Purification KIT (EuRx Ltd., Gdańsk, Poland) according to the manufacturer's recommendations with the modification described by Shah et al. [47]. The dnaJ primers SA-(F) 5'-GCC AAA AGA GAC TATTAT GA-3' and SA-(R) 5'-ATT GTT TAC CTG TTT GTG TAC C-3' were used to amplify the dnaJ gene fragment. The PCR amplification was performed using $10 \times$ PCR RED master mix kit (BLIRT SA, Gdańsk, Poland) in a MJ Mini Personal Thermal Cycler (Bio-Rad, Hercules, CA, USA). PCR products were visualized under UV light following the electrophoretic separation in a $1.5 \%$ agarose gel (Promega, Madison, WI, USA) with ethidium bromide (Promega). To identify staphylococci strains, the PCR products were treated with 10U of restriction enzymes XapI and Bsp143I (Fermentas, Vilnius, Lithuania). The obtained fragments were separated by electrophoresis in a $2 \%$ agarose gel with ethidium bromide (Promega), visualized under the UV light and their size was checked against $1 \mathrm{~Kb}$ HypeLadderIV (BLIRT SA, Gdańsk, Poland) molecular weight marker.

\subsection{Determination of Methicillin Resistance Profiles}

Disk diffusion method with a $30 \mu \mathrm{g}$ disc of cefoxitin (EMAPOL, Gdańsk, Poland) and Mueller-Hinton Agar (MHA-BTL, Łódź, Poland) was used to determine resistance phenotype to methicillin. MRSA strains were detected using a breakpoint of $\leqslant 22 \mathrm{~mm}$ zone diameter size for cefoxitin disk.

The mecA gene detection was performed by PCR amplification according to the method described by Murakami et al. [48]. The following mecA primers (F) (5'-AAA ATC GAT GGT AAA GGT TGG C-3') and (R) (5'-AGT TCT GCA GTA CCG GAT TTG C-3') were used. The PCR reaction was carried out using 10× PCR RED master mix kit (BLIRT SA) in a MJ Mini Personal Thermal Cycler (Bio-Rad, Hercules, CA, USA). The amplicons were detected under UV light after electrophoresis in $1.5 \%$ agarose gel with ethidium bromide (Promega).

\subsection{Disk Diffusion Method}

The antibacterial susceptibility of examined strains to $\mathrm{MLS}_{\mathrm{B}}$ antibiotics was examined by a disk-diffusion method and interpreted according to the EUCAST guidelines [44] with antibiotic discs (EMAPOL) with 15 clindamycin $\mu \mathrm{g}$ (DA), $2 \mu \mathrm{g}$ erythromycin (E) and Mueller-Hinton Agar (MHA-BTL). The distance between the edges of disks was 15-16 mm, according to EUCAST recommendation. The staphylococci were classified as resistant or sensitive based on the zone diameter size and shape.

\subsection{Microdilution Method}

MIC is the lowest concentration of an antimicrobial that will inhibit the visible growth of a microorganism. MICs indicate and confirm the resistance of microorganisms to an antimicrobial agent and also to determine the potency of new antimicrobial agents [49]. In the presented study MICs were defined as the lowest $\mathrm{CH}$ concentration that yielded no visible growth after $24 \mathrm{~h}$ of incubation [50,51]The MICs of CH were determined by a microtiter broth dilution method. The growth inhibition assays were performed in sterile 96-well plates (FL Medical, Torreglia, Italy) in a final volume of $200 \mu \mathrm{L}$ [50,51]. The cell concentrations were estimated from the optical densities at $600 \mathrm{~nm}$ wavelength with the formula $\mathrm{CFU} / \mathrm{mL}=A_{600}\left(3.8 \times 10^{8}\right)$, where CFU was the number of colony-forming units. One hundred microliters of mid-logarithmic-phase bacterial cultures $\left(5 \times 10^{5} \mathrm{CFU} / \mathrm{mL}\right)$ in TSB was added to $100 \mu \mathrm{L}$ of sterile dilutions of $\mathrm{CH}(2,4,8,16,32,64,128$, 256, 1024 and $2048 \mu \mathrm{g} / \mathrm{mL}$ ). Wells containing TSB with bacterial inoculum only served as a bacterial 
growth control (GC). The additional controls included TSB alone (medium sterility control) and TSB with different concentrations of $\mathrm{CH}$ and bacterial inoculum. All samples were prepared in triplicates. Microplates were incubated at $37^{\circ} \mathrm{C}$ for $24 \mathrm{~h}$, and the bacterial cell growth was assessed by measuring the optical density of cultures at $600 \mathrm{~nm}$ wavelength with a Multiskan EX microplate reader (Thermo Electron Corp., Vantoa, Finland) [52,53].

\subsection{The Synergistic Effect of $\mathrm{CH}$ and Antibiotics}

All analyzed strains were examined for the susceptibility to antibiotics by the E-test, using MHA and commercially available MIC Test Strips (Liofilchem, Roseto Degli Abruzzi, Italy) containing antibiotic concentration gradient according to the EUCAST recommendations [44]. For E-test, $90 \mathrm{~mm}$ plates with the agar medium were inoculated by swabbing the agar with a swab soaked in a bacterial suspension of $1 \times 10^{8}$ cells $/ \mathrm{mL}$. MIC Test Strips containing concentration gradient of erythromycin (E), clindamycin (DA), cefoxitin (FOX) and vancomycin (VA) were used for the analysis of antibacterial susceptibility of $S$. aureus strains. The combined effect of $\mathrm{CH}$ and antibiotics was examined using plates with MHA plus one-fourth of the MIC of $\mathrm{CH}$, which was considered as a sub-inhibitory concentration $[54,55]$. The test strips were placed onto an agar surface and gently pressed with the sterile forceps to ensure the contact. Plates were incubated at $35^{\circ} \mathrm{C}$ for $20 \mathrm{~h}$ in aerobic conditions. The susceptibility testing of each antibiotic for each isolate and for the reference strains was performed in triplicates. After the incubation MIC values were read and the median values were calculated.

\subsection{Statistical Analysis}

To compare MICs and MICs changes across MRSA and MSSA U Mann-Whitney test was used and the Kruskal-Wallis test was used to compare MICs and MICs changes across MLS $_{B}$ negative, kMLS $_{B}$ and iMLS ${ }_{B}$ strains. The post-hoc analysis was carried out using Bonferroni correction. The results from the synergism assay were submitted to the Wilcoxon Signed-Rank Test. For all used tests $p \leqslant 0.05$ was considered as statistically significant. The data was analyzed with the use of STATISTICA v 10.0 software (StatSoft, Krakow, Poland) and Windows 10.

\section{Conclusions}

Our data showed that MSSA and MRSA clinical strains are susceptible to $\mathrm{CH}$. This antimicrobial effect of $\mathrm{CH}$ varied across analyzed strains, probably due to intra-species diversity. The addition of $\mathrm{CH}$ to MHA significantly increased erythromycin and clindamycin antimicrobial activity. The synergy of $\mathrm{CH}$ and antibiotics activity in vitro can indicate the potential role of $\mathrm{CH}$ as a factor capable to augment the antibacterial activity of selected antibiotics in vivo.

Acknowledgments: This study was supported by the research grant from Medical University of Silesia NO. KNW-1- 035/N/5/0 and KNW-2-032/D/5/N.

Author Contributions: Maria Miklasińska, Małgorzata Kępa, and Tomasz J. Wasik conceived and designed the experiments; Maria Miklasińska, Małgorzata Kępa, Robert D. Wojtyczka, Danuta Idzik, Arkadiusz Dziedzic performed the experiments; Maria Miklasińska, Małgorzata Kępa and Tomasz J. Wasik analyzed the data; Maria Miklasińska, Małgorzata Kępa and Tomasz J. Wassik wrote the paper.

Conflicts of Interest: The authors declare no conflict of interest.

\section{Abbreviations}

The following abbreviations are used in this manuscript:

$\begin{array}{ll}\text { CFU } & \text { colony forming-unit } \\ \mathrm{CH} & \text { catechin hydrate } \\ \mathrm{DA} & \text { clindamycin } \\ \text { E } & \text { erythromycin }\end{array}$

EUCAST European Committee for Antimicrobial Susceptibility Testing 


$\begin{array}{ll}\text { FOX } & \text { cefoxitin } \\ \text { iMLS }_{B} & \text { inducible macrolide, lincosamide and streptogramin B mechanism } \\ \text { kMLS }_{B} & \text { constitutive macrolide, lincosamide and streptogramin B mechanism } \\ \text { MHA } & \text { Mueller-Hinton agar } \\ \text { MIC } & \text { minimal inhibitory concentration } \\ \text { MRSA } & \text { methicillin resistance Staphylococcus aureus } \\ \text { MSSA } & \text { methicillin susceptible Staphylococcus aureus } \\ \text { VA } & \text { vancomycin }\end{array}$

\section{References}

1. Wojtyczka, R.D.; Dziedzic, A.; Kępa, M.; Kubina, R.; Kabała-Dzik, A.; Mularz, T.; Idzik, D. Berberine enhances the antibacterial activity of selected antibiotics against coagulase-negative Staphylococcus strains in vitro. Molecules 2014, 19, 6583-6596. [CrossRef] [PubMed]

2. Murray, P.R.; Rosenthal, K.S.; Pfaller, M.A. Mikrobiologia; Elsevier Urban \& Partner: Wrocław, Poland, 2011; Volume 6, pp. 161-164, 195-203 and 205-210.

3. Qin, R.; Xiao, K.; Li, B.; Jiang, W.; Peng, W.; Zheng, J.; Zhou, H. The combination of catechin and epicatechin callate from Fructus Crataegi potentiates beta-lactam antibiotics against methicillin-resistant staphylococcus aureus (MRSA) in vitro and in vivo. Int. J. Mol. Sci. 2013, 14, 1802-1821. [CrossRef] [PubMed]

4. Taylor, P.W.; Stapleton, P.D.; Paul Luzio, J. New ways to treat bacterial infections. Drug Discov. Today 2002, 7, 1086-1091. [CrossRef]

5. Kyaw, B.M.; Arora, S.; Lim, C.S. Bactericidal antibiotic-phytochemical combinations against methicillin resistant Staphylococcus aureus. Braz. J. Microbiol. 2012, 43, 938-945. [CrossRef] [PubMed]

6. Wojtyczka, R.D.; Dziedzic, A.; Idzik, D.; Kępa, M.; Kubina, R.; Kabała-Dzik, A.; Smoleń-Dzirba, J.; Stojko, J.; Sajewicz, M.; Wasik, T.J. Susceptibility of Staphylococcus aureus clinical isolates to propolis extract alone or in combination with antimicrobial drugs. Molecules 2013, 18, 9623-9640. [CrossRef] [PubMed]

7. Chan, B.C.; Ip, M.; Lau, C.B.; Lui, S.L.; Jolivalt, C.; Ganem-Elbaz, C.; Litaudon, M.; Reiner, N.E.; Gong, H.; See, R.H.; et al. Synergistic effects of baicalein with ciprofloxacin against NorA over-expressed methicillin-resistant Staphylococcus aureus (MRSA) and inhibition of MRSA pyruvate kinase. J. Ethnopharmacol. 2011, 137, 767-773. [CrossRef] [PubMed]

8. Cushnie, T.P.; Lamb, A.J. Recent advances in understanding the antibacterial properties of flavonoids. Int. J. Antimicrob. Agents 2011, 38, 99-107. [CrossRef] [PubMed]

9. Qiu, J.; Jiang, Y.; Xia, L.; Xiang, H.; Feng, H.; Pu, S.; Huang, N.; Yu, L.; Deng, X. Subinhibitory concentrations of licochalcone A decrease alpha-toxin production in both methicillin-sensitive and methicillin-resistant Staphylococcus aureus isolates. Lett. Appl. Microbiol. 2010, 50, 223-229. [CrossRef] [PubMed]

10. Zhou, T.; Deng, X.; Qiu, J. Antimicrobial activity of Licochalcone E against Staphylococcus aureus and its impact on the production of staphylococcal alpha-toxin. J. Microbiol. Biotechnol. 2012, 22, 800-805. [CrossRef] [PubMed]

11. Borges, A.; Ferreira, C.; Saavedra, M.J.; Simões, M. Antibacterial activity and mode of action of ferulic and gallic acids against pathogenic bacteria. Microb. Drug Resist. 2013, 19, 256-265. [CrossRef] [PubMed]

12. Cushnie, T.P.; Lamb, A.J. Antimicrobial activity of flavonoids. Int. J. Antimicrob. Agents 2005, 26, 343-356. [CrossRef] [PubMed]

13. Luís, Â.; Silva, F.; Sousa, S.; Duarte, A.P.; Domingues, F. Antistaphylococcal and biofilm inhibitory activities of gallic, caffeic, and chlorogenic acids. Biofouling 2014, 30, 69-79. [CrossRef] [PubMed]

14. Borges, A.; Saavedra, M.J.; Simões, M. The activity of ferulic and gallic acids in biofilm prevention and control of pathogenic bacteria. Biofouling 2012, 28, 755-767. [CrossRef] [PubMed]

15. Miklasińska, M.; Kępa, M.; Wojtyczka, R.D.; Idzik, D.; Zdebik, A.; Orlewska, K.; Wąsik, T.J. Antibacterial activity of protocatechuic acid ethyl ester on Staphylococcus aureus clinical strains alone and in combination with antistaphylococcal drugs. Molecules 2015, 20, 13536-13549. [CrossRef] [PubMed]

16. Yilmaz, Y. Novel uses of catechin in foods. Trends Food Sci. Technol. 2006, 17, 64-71. [CrossRef] 
17. Moini, H.; Guo, Q.; Packe, L. Xanthine oxidase and xanthine dehydrogenase inhibition by the procyanidin-rich French maritime pine bark extract, pycnogenol: A protein binding effect. Adv. Exp. Med. Biol. 2002, 505, 141-149. [PubMed]

18. Scott, B.C.; Butler, J.; Halliwell, B.; Aruoma, O.I. Evaluation of the antioxidant actions of ferulic acid and catechins. Free Radic. Res. Commun. 1993, 19, 241-253. [CrossRef] [PubMed]

19. Fukumoto, L.R.; Mazza, G.J. Assessing antioxidant and prooxidant activities of phenolic compounds. J. Agric. Food Chem. 2000, 48, 3597-3604. [CrossRef] [PubMed]

20. Morel, I.; Lescoat, G.; Cogrel, P.; Sergent, O.; Pasdeloup, N.; Brissot, P.; Cillard, P.; Cillard, J. Antioxidant and iron-chelating activities of the flavonoids catechin, quercetin and diosmetin on iron-loaded rat hepatocyte cultures. Biochem. Pharmacol. 1993, 45, 13-19. [CrossRef]

21. Holloway, A.C.; Mueller-Harvey, I.; Gould, S.W.J.; Fielder, M.D.; Naughton, D.P.; Kelly, A.F. The effect of copper(II), iron(II) sulphate, and vitamin C combinations on the weak antimicrobial activity of (+)-catechin against Staphylococcus aureus and other microbes. Metallomics 2012, 4, 1280-1286. [CrossRef] [PubMed]

22. Al-Hazzani, A.A.; Alshatwi, A.A. Catechin hydrate inhibits proliferation and mediates apoptosis of $\mathrm{SiHa}$ human cervical cancer cells. Food Chem. Toxicol. 2011, 49, 3281-3286. [CrossRef] [PubMed]

23. Alshatwi, A.A. Catechin hydrate suppresses MCF-7 proliferation through TP53/Caspase-mediated apoptosis. J. Exp. Clin. Cancer Res. 2010, 17, 167. [CrossRef] [PubMed]

24. Moore, P.S.; Pizza, C. Observations on the inhibition of HIV-1 reverse transcriptase by catechins. Biochem. J. 1992, 15, 717-719. [CrossRef]

25. Yam, T.S.; Hamilton-Miller, J.M.; Shah, S. The effect of a component of tea (Camellia sinensis) on methicillin resistance, PBP2' synthesis, and beta-lactamase production in Staphylococcus aureus. J. Antimicrob. Chemother. 1998, 42, 211-216. [CrossRef] [PubMed]

26. Stapleton, P.D.; Shah, S.; Hamilton-Miller, J.M.; Hara, Y.; Nagaoka, Y.; Kumagai, A.; Uesato, S.; Taylor, P.W. Anti-Staphylococcus aureus activity and oxacillin resistance modulating capacity of 3-O-acyl-catechins. Int. J. Antimicrob. Agents 2004, 24, 374-380. [CrossRef] [PubMed]

27. Caturla, N.; Vera-Samper, E.; Villalaín, J.; Mateo, C.R.; Micol, V. The relationship between the antioxidant and the antibacterial properties of galloylated catechins and the structure of phospholipid model membranes. Free Radic. Biol. Med. 2003, 34, 648-662. [CrossRef]

28. Ikigai, H.; Nakae, T.; Hara, Y.; Shimamura, T. Bactericidal catechins damage the lipid bilayer. Biochim. Biophys. Acta 1993, 1147, 132-136. [CrossRef]

29. Kajiya, K.; Kumazawa, S.; Nakayama, T. Steric effects on interaction of tea catechins with lipid bilayers. Biosci. Biotechnol. Biochem. 2001, 65, 2638-2643. [CrossRef] [PubMed]

30. Kajiya, K.; Kumazawa, S.; Nakayama, T. Effects of external factors on the interaction of tea catechins with lipid bilayers. Biosci. Biotechnol. Biochem. 2002, 66, 2330-2335. [CrossRef] [PubMed]

31. Stapleton, P.D.; Shah, S.; Anderson, J.C.; Hara, Y.; Hamilton-Miller, J.M.; Taylor, P.W. Modulation of beta-lactam resistance in Staphylococcus aureus by catechins and gallates. Int. J. Antimicrob. Agents 2004, 23, 462-467. [CrossRef] [PubMed]

32. Stapleton, P.D.; Taylor, P.W. Methicillin resistance in Staphylococcus aureus: Mechanisms and modulation. Sci. Prog. 2002, 85, 57-72. [CrossRef] [PubMed]

33. Zhao, W.H.; Hu, Z.Q.; Okubo, S.; Hara, Y.; Shimamura, T. Mechanism of synergy between epigallocatechin gallate and beta-lactams against methicillin-resistant Staphylococcus aureus. Antimicrob. Agents Chemother. 2001, 45, 1737-1742. [CrossRef] [PubMed]

34. Bernal, P.; Lemaire, S.; Pinho, M.G.; Mobashery, S.; Hinds, J.; Taylor, P.W. Insertion of epicatechin gallate into the cytoplasmic membrane of methicillin-resistant Staphylococcus aureus disrupts penicillin-binding protein (PBP) 2a-mediated beta-lactam resistance by delocalizing PBP2. J. Biol. Chem. 2010, 285, 24055-24065. [CrossRef] [PubMed]

35. Gibbons, S.; Moser, E.; Kaatz, G.W. Catechin gallates inhibit multidrug resistance (MDR) in Staphylococcus aureus. Planta Med. 2004, 70, 1240-1242. [CrossRef] [PubMed]

36. Shiota, S.; Shimizu, M.; Mizushima, T.; Ito, H.; Hatano, T.; Yoshida, T.; Tsuchiya, T. Marked reduction in the minimum inhibitory concentration (MIC) of beta-lactams in methicillin-resistant Staphylococcus aureus produced by epicatechin gallate, an ingredient of green tea (Camellia sinensis). Biol. Pharm. Bull. 1999, 22, 1388-1390. [CrossRef] [PubMed] 
37. Hamilton-Miller, J.M.; Shah, S. Activity of the tea component epicatechin gallate and analogues against methicillin-resistant Staphylococcus aureus. J. Antimicrob. Chemother. 2000, 46, 852-853. [CrossRef] [PubMed]

38. Kubo, I.; Xiao, P.; Fujita, K. Anti-MRSA activity of alkyl gallates. Bioorg. Med. Chem. Lett. 2002, 12, 113-116. [CrossRef]

39. Hu, Z.Q.; Zhao, W.H.; Asano, N.; Yoda, Y.; Hara, Y.; Shimamura, T. Epigallocatechin gallate synergistically enhances the activity of carbapenems against methicillin-resistant Staphylococcus aureus. Antimicrob. Agents Chemother. 2002, 46, 558-560. [CrossRef] [PubMed]

40. Hu, Z.Q.; Zhao, W.H.; Hara, Y.; Shimamura, T. Epigallocatechin gallate synergy with ampicillin/sulbactam against 28 clinical isolates of methicillin-resistant Staphylococcus aureus. J. Antimicrob. Chemother. 2001, 48, 361-364. [CrossRef] [PubMed]

41. Vandeputte, O.M.; Kiendrebeogo, M.; Rajaonson, S.; Diallo, B.; Mol, A.; El Jaziri, M.; Baucher, M. Identification of catechin as one of the flavonoids from Combretum albiflorum bark extract that reduces the production of quorum-sensing-controlled virulence factors in Pseudomonas aeruginosa PAO1. Appl. Environ. Microbiol. 2010, 76, 243-253. [CrossRef] [PubMed]

42. Choi, O.; Yahiro, K.; Morinaga, N.; Miyazaki, M.; Noda, M. Inhibitory effects of various plant polyphenols on the toxicity of Staphylococcal alpha-toxin. Microb. Pathog. 2007, 42, 215-224. [CrossRef] [PubMed]

43. Loes, A.N.; Ruyle, L.; Arvizu, M.; Gresko, K.E.; Wilson, A.L.; Deutch, C.E. Inhibition of urease activity in the urinary tract pathogen Staphylococcus saprophyticus. Lett. Appl. Microbiol. 2014, 58, 31-41. [CrossRef] [PubMed]

44. European Committee for Antimicrobial Susceptibility Testing (EUCAST) of the European Society of Clinical Microbiology and Infectious Diseases (ESCMID). Terminology relating to methods for the determination of susceptibility of bacteria to antimicrobial agents. EUCAST definitive document E. Def 1.2. Clin. Microbiol. Infect. 2000, 6, 503-508.

45. Taylor, P.W.; Hamilton-Miller, J.M.T.; Stapleton, P.D. Antimicrobial properties of green tea catechins. Food Sci. Technol. Bull. 2005, 2, 71-81. [CrossRef] [PubMed]

46. Park, K.D.; Cho, S.J. Synthesis and antimicrobial activities of 3-O-alkyl analogues of (+)-catechin: Improvement of stability and proposed action mechanism. Eur. J. Med. Chem. 2010, 45, 1028-1033. [CrossRef] [PubMed]

47. Shah, M.M.; Iihara, H.; Noda, M.; Song, S.X.; Nhung, P.H.; Ohkusu, K.; Kawamura, Y.; Ezaki, T. dnaJ gene sequence-based assay for species identification and phylogenetic grouping in the genus Staphylococcus. Int. J. Syst. Evol. Microbiol. 2007, 57, 25-30. [CrossRef] [PubMed]

48. Murakami, K.; Minamide, W.; Wada, K.; Nakamura, E.; Teraoka, H.; Watanabe, S. Identification of methicillin-resistant strains of Staphylococci by polymerase chain reaction. J. Clin. Microbiol. 1991, 29, 2240-2244. [PubMed]

49. Andrews, J.M. Determination of minimum inhibitory concentrations. J. Antimicrob. Chemoter. 2001, 48, 5-16. [CrossRef]

50. Amsterdam, D. Susceptibility testing of antimicrobials in liquid media. In Antibiotics in Laboratory Medicine, 5th ed.; Loman, V., Ed.; Williams and Wilkins: Philadelphia, PA, USA, 2005; pp. 61-143.

51. European Committee for Antimicrobial Susceptibility Testing (EUCAST) of the European Society of Clinical Microbiology and Infectious Diseases (ESCMID). Determinantion of minimum inhibitory concentrations (MICs) of antibacterial agents by broth dilution. EUCAST discussion document E. Dis 5.1. Clin. Microbiol. Infect. 2003, 9. [CrossRef]

52. Cudic, M.; Condie, B.A.; Weiner, D.J.; Lysenko, E.S.; Xiang, Z.Q.; Insug, O.; Bulet, P.; Otvos, L., Jr. Development of novel antibacterial peptides that kill resistant clinical isolates. Peptides 2002, 23, 2071-2083. [CrossRef]

53. Devienne, K.F.; Raddi, M.S.G. Screening for antimicrobial activity of natural Products using a microplate photometer. Braz. J. Microbiol. 2002, 33, 166-168. [CrossRef]

54. Fernandes, A., Jr.; Balestrin, E.C.; Betoni, J.E.C.; Orsi, R.O.; da Cunha, M.R.S.; Montelli, A.C. Propolis: Anti-Staphylococcus aureus activity and synergism with antimicrobial drugs. Mem. Inst. Os. Cruz 2005, 100, 563-566. [CrossRef] 
55. Mahon, C.R.; Manuselis, J.R.G. Textbook of Diagnostic Microbiology; W.B. Saunders: Philadelphia, PA, USA, 1995.

Sample Availability: Samples of the compounds and clinical strains are available from the authors.

(C) 2016 by the authors; licensee MDPI, Basel, Switzerland. This article is an open access article distributed under the terms and conditions of the Creative Commons by Attribution (CC-BY) license (http://creativecommons.org/licenses/by/4.0/). 